\title{
Bilişsel ve Fizyolojik Destek Sistemi Olarak Dijital Oyun Uygulamalarının Sistematik Analizi
}

Umut ÇARDAK, Van Yüzüncü Yıl Üniversitesi Eğitim Bilimleri Enstitüsü, umut_cardak@hotmail.com, ORCID: 0000-0003-4366-5179

Muhammed ÖZBEY, Van Yüzüncü Yıl Üniversitesi, Eğitim Bilimleri Enstitüsü, muhammedozbey65@gmail.com, ORCID: 0000-0003-4162-1842

$\ddot{O Z Z}$

Teknoloji günümüz çă̆ında hızla gelişmektedir ve bu gelişmenin să̆llk alanındaki yansıması kaçınılmazdır. Teknolojinin să̆lık alanındaki yansıması cerrahi alanda olduğu kadar standart tedavilerde de kendini göstermektedir. Fizyolojik ve bilişsel tedavilerde teknolojinin kullanımı, elektronik ve dijital ortamların geliştirilmesi ve să̆lık alanına daha çok uygulanmaya başlaması ile bariz bir şekilde kendini göstermektedir. Să̆lık alanında teknolojinin kullanıldığ alanlardan biri de çeşitli hastalıklarm tedavi edilebilmesi amacı ile geliştirilen dijital oyunlar ve beraberinde kullanıldı̆̆ $ı$ cihazlardır. Bu çalışmanın amacl; bilişsel ve fizyolojik destek sistemi olarak dijital oyunların sağlık alanında kullanımını gerçekleştiren deneysel çalışmaların sistematik analizin yapılarak sonuçlarının incelenmesidir. Bu kapsamda 20002019 yılları arasında ulusal ya da uluslararası dergilerde yayımlanmış makaleler, konu ile ilgili yapılan lisansüstü tez çalışmaları ve çeşitli kongrelerde sunulan bildiriler çalışma kapsaminda incelenmiş, deneysel bir yöntem kullanan ve spesifik olarak bir dijital oyun platformu içeren 21 araştırma çalışmaya dahil edilmiştir. Analiz sonunda elde edilen bulgular tartışılarak oyunların sağlık alanında kullanımına ilişkin bazı önerilerde bulunulmuştur.

\section{Anahtar : Dijital Oyunlar, Sağlık, Tedavi, Bilişsel, Fizyolojik \\ Kelimeler \\ Systematic Analysis Of Digital Game Applications As Cognitive And Physiological Support System}

\begin{abstract}
Technology is developing rapidly in today's age and the reflection of this development in the field of health is inevitable. The reflection of technology in the field of health is reflected in standard treatments as well as in the surgical field.The use of technology in physiological and cognitive therapies is evident with the development of electronic and digital environments and the introduction of more healthcare applications. One of the areas where technology is used in the field of health is digital games developed with the aim of treating various diseases and the devices used with them. The purpose of this study; The cognitive and physiological support system is the systematic analysis of experimental studies that make use of digital games in the field of health, and the results are examined. In this context, articles published in national or international journals between 2000-2019, postgraduate thesis studies on the subject and papers presented in various congresses were examined within the scope of the study, and 21 studies that specifically use a digital game platform were included in the study. The findings obtained at the end of the analysis were discussed and some suggestions were made regarding the use of games in the field of health.
\end{abstract}

Keywords : Digital Games, Health, Treatment, Cognitive, Physiological 


\section{GİRIŞ}

Oyunlar insanların eğlendikleri, hoş zaman geçirdikleri etkinliklerdir (Huizinga, 1938). Genellikle çocuklarla özdeşleşen ve fiziksel ortamda oynanan oyun kavramı teknolojinin gelişimi ve yaygınlaşması ile birlikte yepyeni bir kimliğe bürünmüştür. Dijital çağ olarak da bilinen 21. yüzyıl dünyasında oyuna ait birçok şey değişmiş ve "dijital oyunlar" böylece insan hayatında yerini almıştır. Bilgisayar oyunları, konsol oyunları, mobil oyunlar, sanal gerçeklik oyunları, artırılmış gerçeklik oyunları gibi oynanan platform ve ekipmana göre birçok biçimi bulunan dijital oyunlar, her geçen gün daha fazla kullanıcı tarafından oynanmaktadır (Güvenli İnternet Merkezi, 2019). Artan kullanımla beraber firmalar, ticari amaçlarla sadece oyun oynamaya yönelik Kinect, Xbox, Wii, Playstation gibi platform ve ekipman üretmeye başlamışlardır. Hatta günümüzde bu platformların bazıları hiçbir ekipman-donanım kullanılmadan sadece ekran aracılığı ile insan bedeni ile yönlendirme sağlanarak oynanabilmektedir (Xbox, 2019).

Eğitimden orduya, yönetişimden iş yaşamına kadar birçok alanda görülen dijital oyun kullanımı, sağlık alanında da son dönemde öne çıkmaktadır. Sağlık oyunları bir yandan kullanıcılara sağlıklı yaşam için ipuçlarını eğlenceli bir biçimde sunarken; öte yandan bedenin işleyişine yönelik temel bilgileri de öğretmektedir (Avcı\& Avşar, 2016). Bu bağlamda sağlık alanında oyunlar yaşam kalitesini arttırma, fizik tedavi ve rehabilitasyon, çeşitli hastalıklar hakkında bilgi edinme ve onlarla mücadele yollarını öğrenme gibi birçok alanda kullanılabilmektedir (Thompson, Baranowski, Buday, Baranowski, Thompson, Jago\& Griffith, 2010).

\subsection{Aktif Video Oyunlan ve Ĕ̆itim:}

Oyunlar, çocuklarda motivasyonu ve güdülenmişlik düzeyini artırır; konuya ilgi duymasını sağlar ve çocuklarda rahatlama meydana gelir (Bayırtepe ve Tüzün, 2007). Aktif video oyunları, bireylerin hareketli bir şekilde ve eğlenerek oyun oynamalarını sağlayan ve oyun süresince aktif olmasını gerektiren eğlenceli video oyunlarıdır (Hansen ve Sanders, 2008). Bu tür oyunlarda kullanıcı fiziksel olarak sabit kalmaz, oyundaki avatar, karakter, nesne vs. varlıkları kendi bedeni ile yönlendirir.

En popüler Aktif Video Oyun Platformlarından ikisi olan Nintendo Wii ve Microsoft XBox Kinect, oynatıcının kendi oyunlarıyla nasıl etkileşimde bulunduğuna bağlı olarak farklı teknolojiler kullanmaktadır. Wii, oynatıcı hareketlerini algılamak için video görüntüleme ekranında veya yakınında bir sensör çubuğuyla iletişim kuran el tipi bir kablosuz kumanda kullanmakta, buna karşın Kinect elde tutulan bir kontrol cihazı yerine kızılötesi hareket sensörü ve oyunu oynayan kişinin üç boyutlu gösterimini yaratabilen kırmızı yeşil-mavi bir web kamerası kullanmaktadır. Kinect oynatılırken, kullanıcının vücut hareketi baştan ayağa üç boyutlu olarak yakalanır (Marks, Rispen\& Calara, 2015). 
2011 yılında Ankara'da yapılan bir araştırmada okul öncesi çocukların hareket edeceği ve oyun oynayacağı alanların oldukça kısıtlı olması, öğretmenlerin ve ebeveynlerin hareket eğitimi konusunda bilgilerinin az olmasından dolayı çocukların hareketsiz bir yaşam sürdürdüklerini bundan dolayı okul öncesi okullarda hareket eğitimi açısından acil değişiklikler yapılması gerektiği vurgulanmıştır (Sevimli-Celik, Kirazci ve Ince, 2011). Bu gereklilik ile Aktif Video Oyunları, günümüzde öğretim ortamı olarak görülmekte ve teknolojiyi bilgi yapısını desteklemek için araç olarak kullanan öğretim uygulamalarıyla ilişkilendirmektedir (Birn, Holzmann ve Stech, 2014). Aktif Video Oyunlarının bir egzersiz şekli olarak kullanılması motor öğrenmenin temel öğelerini içerir (Yen ve diğerleri, 2009). Görevlerin ve faaliyetlerin gerçek zamanlı pratiğinin yanı sıra, gerçek hayattaki ilgi alanlarıyla ilgili yoğun, anlamlı, eğlenceli ve amaçlı görevlerde bulunma fırsatları sunar (Vernadakis, Gioftsidou, Antoniou, Ioannidis ve Giannousi, 2012; Yen ve ark., 2011). Bu faaliyetlerin uygulanması, çocuğun motivasyonunu artırabileceği ve çocuğun eğitim programının bir parçasını oluşturabileceği için ümit vericidir.

\subsection{Ciddi Oyunlar ve Sağlık:}

Oyunların insanlar üzerinde etkileri olduğuna dair yapılan birçok akademik çalışma mevcuttur (Emmelkamp, Bruynzeel, Drost\& van der Mast, 2001; Valladares-Rodriguez, Fernández-Iglesias, Anido-Rifón, Facal, Rivas-Costa\& Pérez-Rodríguez, 2019). Çalışmalarda bu etkilerin bilişsel, duyuşsal veya psikomotor alanlarda olumlu veya olumsuz yönde olduğu görülür (Grossard, Grynspan, Serret, Jouen, Bailly\& Cohen, 2017). Oyunların bu etkileri zamanla irdelenmiş ve dijital oyunlar sadece bir eğlence aracı olmaktan çıkıp eğitim, iş yaşamı, yönetim, ordu gibi birçok alanda kullanılmaya başlanmıştır. Bu alanlardan bir diğeri ve en yenilerinden biri de "sağlık" alanıdır. Zaten literatürde "Ciddi Oyun" olarak tanımlanan oyunların temel amacı da bilgi ya da eğitim becerilerini öğreterek saf eğlencenin ötesine geçmektir (Fuchslocher, Niesenhaus\& Krämer, 2011). Bu da oyunların sağlık alanında çeşitli amaçlarla kullanımına dair çalışmalar yapılması konusunda araştırmacılara kaynak düşünce olmaktadir.

Sağlık alanında oyunlar, sağlık personeli eğitimi, belirli hastalıkların tedavisi, fizik tedavi ve rehabilitasyon gibi amaçlarla kullanılmakta ve bu kullanım amaçları ile oyunlar gelecek adına umut vaat etmektedir (Betker, Szturm, Moussavi\& Nett, 2006; Cannon-Bowers, Bowers\& Procci, 2011). Ancak bu araştırma kapsamında belirtilen amaçlardan oyunların tedavi ve rehabilitasyon amaçlı kullanımı kapsamında yapılan çalışmalar incelenmiştir. Bu çalışmalara genel bir bakış atılması dijital oyunların tedavilerde nasıl, ne yöntemle, ne amaçla, kimlere, hangi platformlarda kullanıldıklarını ve ne derece etkili olduklarını görmek açısından önemli olacağ1 düşünülmektedir.

Bilişsel ve psikomotor destek sistemi olarak dijital oyunların , "İhmal sendromu" (Surer, Pirovano, Mainetti, Tatti, Baud-Bovy\& Borghese, 2014) ve "alzheimer" (Valladares-Rodriguez 
vd., 2019) gibi bilişsel, “otizm” (Grossard vd., 2017) gibi gelişimsel, “akrofobi” (Emmelkamp vd., 2001) gibi psikolojik, "Serebral Palsi" (Ciddi, 2018; Kaya\& Y1lmaz, 2018) ve "Parkinson" (Allen, Song, Paul, Smith, O'Duffy, Schmidt\& Canning, 2017) gibi nörolojik ve "KOAH" (Sutanto, Makhabah, Aphridasari, Doewes\& Ambrosino, 2019), "hemodinamik bozukluk" (Brito-Gomes, Perrier-Melo, Brito\& Costa, 2018), "kırık tedavisi" (Zago, de Souza, Kimura, Bertoncello, Grecco\& Fernandes, 2019), “Diyabet" (Fuchslocher vd., 2011), “Çoklu skleroz" (Jonsdottir, Perini, Ascolese, Bowman, Montesano, Lawo\& Bertoni, 2019) gibi fizyolojik hastalık ve problemlerde tedavi ve rehabilitasyon amacıyla kullanımına ilişkin araştırmalar yapılmıştır. Bu Çalışmalarda genellikle Nitendo Wii (Ciddi, 2018), Kinect (Surer vd., 2014) ve sanal gerçeklik uygulamaları (Emmelkamp vd., 2001) kullanılmıştır. Araştırmalardan bazıları oyunların tedavi edici etkilerinin olduğu bulgusuna ulaşırken (Jonsdottir vd., 2019), bazıları tedavi sürecine anlamlı düzeyde bir katkı sunmadıkları sonucuna ulaşmıştır (Brito-Gomes vd., 2018). Bazı araştırmaçlar da oyunun tek başına tedavi amaçlı kullanımından ziyade normal tıbbi sürece destek olarak kullanımının daha işlevsel olacağını düşünmektedir (Kaya\& Yılmaz, 2018). Ayrıca dijital oyun platform ve ekipmanlarının maliyetli olması, kullanımın ekonomik olmayacağı görüşünü ortaya çıkarmıştır (Sutanto vd., 2019).

Oyunların tedavi ve rehabilitasyon amaçlı kullanımına dair alan yazında birçok deneysel çalışma ve belirli teknolojilerin hastalıkların tedavisine ilişkin derlemeler (Hall, Chavarria, Maneeratana, Chaney\& Bernhardt, 2012) mevcuttur. Ancak bu derleme çalışmalarında ya sadece kullanılan oyun türüne odaklanılarak çalışılmış (Webster\& Celik, 2014) ya da spesifik bir hastalığa yönelik denenen oyun destekli tedavi çalışmaları incelenmiştir (McCallum\& Boletsis, 2013).

Bilişsel ve fizyolojik destek sistemi olarak denenen oyunların hangi hastalıklarda, hangi örneklem gruplarında, hangi platform ve ekipmanlar kullanılarak araştırıldığı ve araştırma sonuçlarını toplu şekilde ortaya koyan bir çalışmaya rastlanmamıştır. Ayrıca ulusal alanyazında bu çalışmaya benzer içerik analizlerinin sayısının oldukça az olduğu ve mevcut çalışmaların da yalnız tek bir yöne odaklanılarak yapılan analizler olduğu görülmektedir. Alanda sonraki araştırmacılara ışık tutmak gerekçesiyle, bu sistematik analiz çalışması ile yukarıdaki kapsamda bütüncül bir özet sunmak amaçlanmıştır. Bu amaç doğrultusunda aşağıdaki sorulara yanıt aranmıştır:

1- Hastaların tedavi-rehabilitasyon süreçlerinde oyunlar, hangi platform ve ekipmanlar ile uygulanmakta ve etkili olmaktadır?

2- Tedavi ve rehabilitasyon amaçlı uygulanan oyunlar hangi hastalıklar için denenmiş ve etkili olmuştur?

3- Araştırmaların örneklem grubuna göre (çocuk, orta yaş, yaşlı) dağılımı ve etkililik durumu nasildir? 
4- Bu uygulamaların genel sonuçları ve önerileri nelerdir?

\section{YÖNTEM}

Araştırma sorularını yanıtlaması amacıyla oyunların sağlık alanındaki uygulamalarına dair lisansüstü tezler, çevrimiçi makaleler ve bazı sempozyum-konferans bildirileri taranarak içerik analizi (sistematik analiz) yapılmıştır.

\section{1. Örneklem ve Veri Toplama:}

Çalışmaya konuyla ilgili yayınların geriye dönük olarak taranması ile başlanmıştır. Bu amaçla Atatürk Üniversitesi internet ağı üzerinden "Web Of Science”, "Science Direct" , "Scopus", "Yök-Tez", "ULAKBİM" veri tabanları ve "Google Akademik" arama motoru kullanılarak; sağlık (health), tedavi (treatment), rehabilitasyon (rehabilitation), iyileştirici (curative), bakım (cure), terapi (therapy), bilişsel (cognitive), fizyolojik (physiological), oyun (game), video oyunu (videogame), dijital oyun (digital game), sanal gerçeklik (virtual reality), Kinect ve Nintendo Wii gibi anahtar kelimeler ile Türkçe ve İngilizce olarak çeşitli kombinasyonlarda tarama yapılmıştır. Tarama sonucunda 2000-2019 yılları arasında ulusal ya da uluslararası dergilerde yayımlanmış makaleler, konu ile ilgili yapılan lisansüstü tez çalışmaları ve çeşitli kongrelerde sunulan bildiriler çalışma kapsamında incelenmiş, deneysel bir yöntem kullanan ve spesifik olarak bir dijital oyun platformu içeren araştırmalar çalışmaya dahil edilmiştir. Bir oyun platformunun çeşitli tedavilerde kullanımına ilişkin yapılan derleme çalışmaları veya bir hastalığın tedavisi için kullanılan oyunlara ilişkin gözden geçirmeler bu çalışmada ele alınmamıştır. İncelenecek kaynakların çalışmaya dahil edilmesinde kullanılan kriterler Şekil1'deki akış diyagramında gösterilmiştir. 


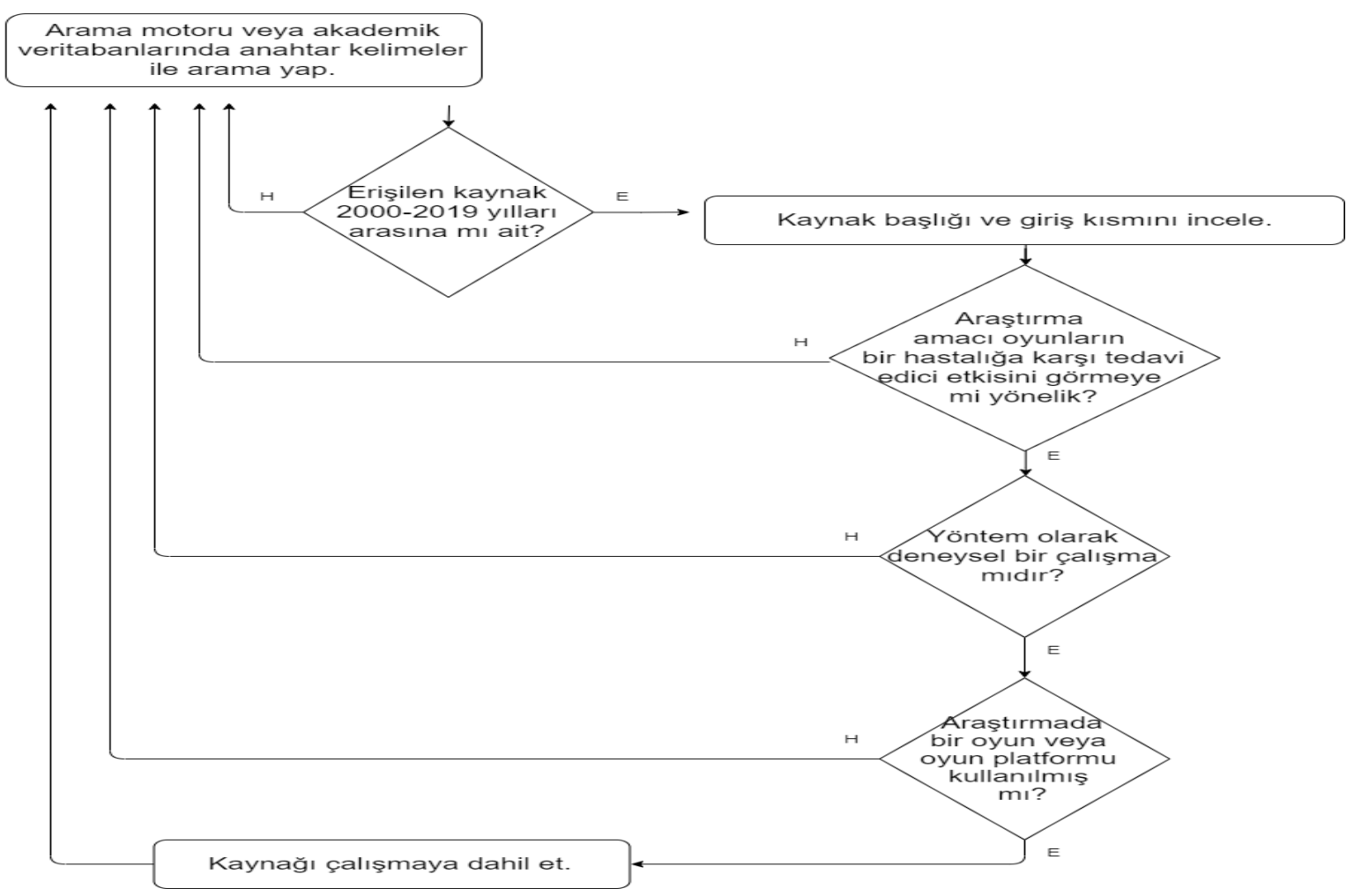

Şekil 1: Çalışmaya dahil edilme kriterlerini gösteren akış diyagramı.

Verilerin toplanması aşamasında yapılan literatür tarama sürecinde erişilen 46 adet yayından 25 tanesi araştırmaya dahil edilme kriterlerine uygun olmadığından değerlendirme dışı bırakılmış, kalan 21 akademik çalışma bu araştırmaya dahil edilmiştir.

\subsection{Veri Analizi:}

Kaynakların derinlemesine incelemesinden önce, verilerin analizini kolaylaştırıcı bir tablo Microsoft Office Excel programı kullanılarak oluşturulmuştur. Tabloda, erişilen yayınların özetini sağlayıcı biçimde şu ana başlıklar kullanılmıştır: "Araştırma Türü", "Araştırma Adı", "Araştırmanın Amacı", "Örneklem Grubu", "Hastalık adı ve Sınıfı"," Yöntem", Kullanılan Ekipman-Platform-Oyun", "Sonuç-Öneriler". İncelenen her yayın sonrasında belirtilen tabloya veriler işlenmiş, buradan elde edilen sonuçlar, sınıflama ve değerlendirmeler bulgular bölümünde tablolar halinde sunulmuştur.

\subsection{Geçerlik ve Güvenirlik:}

Yıldırım ve Şimşek (2005)'e göre geçerlik araştırmanın genellenebilirliği, inandırıcılığı ve doğruluğuyla, güvenirliği ise tekrar edilebilirlik ve tutarlılı̆̆ 1 ile ilgilidir. Nitel bir çalışmada geçerlik ve güvenirliği sağlamak için; uzman görüşü, akran değerlendirmesi, derinlemesine veri toplama, veri toplama ve analiz sürecinin detaylı ve açık bir şekilde anlatılması gibi önlemler alınabilir (Yıldırım \& Şimşek, 2005). Nicel araştırmaların aksine nitel araştırmalarda 
geçerlilik ve güvenilirlik kavramlarının yerine inanılırlık, araştırmacının yetkinliği ve sonuçların doğruluğu gibi kavramlardan bahsetmek daha doğru olacaktır (Krefting, 1991).

Çalışmamızın "Veri Analizi" alt başlığında belirtildiği üzere; analiz sürecini kolaylaştırıcı bir tablo, Microsoft Office Excel programı kullanılarak oluşturulmuştur. İncelenen her yayın sonrasında belirtilen tabloya veriler iki araştırmacı tarafından ayrı ayrı işlenmiştir. İncelenen çalışmalarda kodlamalar sonucu temaların tarafsız ve açık olmasına dikkat edilmiş ve ayrı ayrı işlemeler sonucunda farklılık oluşan kısımlarda uzman görüş desteği alınarak çalışmanın güvenirliği ve geçerliğinin artırılması amaçlanmıştır.

Dijital oyun alanında uzman akademisyen ile uzun süreli etkileşim halinde olunarak, elde edilen veriler ile doküman incelemesi sonucunda ortaya çıkan bulgular referanslar ile desteklenerek inandırıcılığın artırılması hedeflenmiştir. Bunun yanında sürekli literatür taraması yapılarak bilgilerin güncelliği devamlı kontrol altında tutulmuştur.

Araştırmanın güvenirliğinin sağlanması amacıyla araştırma kapsamında incelenen çalışmalara ilişkin bilgiler, tablo ve ek olarak açık bir şekilde paylaşılmıştır. Tüm bu alınan tedbirler ile çalışmanın iç geçerliliği ve güvenirliği sağlanmaya çalışılmıştır.

\section{BULGULAR}

Bu bölümde çalışmamızın giriş bölümünde belirtilen alt problemlere çözüm üretmeye yönelik veri analizlerine dair bulgulara ve yorumlara yer verilmiş olup bu bulgular genellikle tablolar halinde sunulmuştur.

\section{1. Üzerinde Etkisi Araştırılan Hastalık-Sorun Türlerine İlişkin Bulgular:}

İncelenen 21 akademik yayına ait oyunların üzerinde etkisinin araştırıldığ 1 sorun-hastalık türleri ve bunların frekans değerleri Tablo 1'de sunulmuştur.

Tablo 1. Oyunların Tedavi-Rehabilitasyon amaçlı kullanımının hastalık türleri ve adlarına göre dăğılımı

\begin{tabular}{llcc}
\hline Hastalık-Sorun & Hastalık-Sorun Adı: & ToplamFrekans: & Etkili Olan Çalışma \\
\hline Fizyolojk & $\begin{array}{l}\text { Hemodinamik } \\
\text { Bozukluk }\end{array}$ & 1 & 0 \\
KOAH & 2 & 1 \\
Kirık vb. & 3 & 2 \\
Diyabet & 1 & 0 \\
Kanser & 1 & 1
\end{tabular}




\begin{tabular}{llll} 
Bilişsel & İhmal Sendromu & 1 & 1 \\
& Alzheimer & 1 & 1 \\
Nörolojik & Parkinson & 3 & 2 \\
& Perioperatif Ăgrı & 1 & 1 \\
& Denge Kaybı & 1 & 0 \\
& Serebral Palsi & 3 & 3 \\
Psikolojik & Akrofobi & 1 & 1 \\
Gelişimsel & Otizm & 2 & 2 \\
Toplam & & $\mathbf{2 1}$ & $\mathbf{1 5}$ \\
\hline
\end{tabular}

Tablo 1'de görüldüğü oyunların etkisinin araştırıldığ 1 incelenen 21 çalışmadan sekizer tanesi fizyolojik ve nörolojik, ikişer tanesi bilişsel ve gelişimsel ve bir tanesi ise psikolojik bir hastalıksorunu ele almıştır. Hastalık türlerinin bu dağılımına göre araştırma konularına en fazla fizyolojik ve nörolojik hastalıklar, en az ise psikolojik sorunlar dahil edilmiştir. Hastalık türüne göre dağılım bu şekildeyken, spesifik hastalık olarak en fazla üçer çalışma ile Kırık vb. tedaviler, Parkinson ve Serebral Palsi konu olmuştur.

\section{2. Çalışmalarda Kullanılan Platform-Oyun Türlerine İlişkin Bulgular:}

İncelenen yayınlarda tedavi edici ve rehabilitasyon amaciyla kullanılan oyunların sinıflandırılması Tablo 2'de sunulmuştur.

Tablo 2. Tedavi-Rehabilitasyonlarda kullanılan oyun ve platform türlerinin dağılımı

\begin{tabular}{lllc}
\hline Oyun Türü: & Platform: & Frekans: & Etkili Olan Çalışma \\
\hline Aktif (Vücut Sensörlü) Video & Kinect & 5 & 4 \\
& Wii & 8 & 4 \\
Sanal Gerçeklik Oyunları & VR & 2 & 2 \\
Bilgisayar Oyunları & PC & 5 & 4 \\
Mobil Oyunlar & Tablet-Akıllı & 1 & 1
\end{tabular}


Tablo 2'de görüldüğü üzere kullanılan oyun türüne göre en fazla çalışılan oyun türü; Aktif (Vücut Sensörlü) Video Oyunlarıdır. Vücut hareketleri ile oynanan bu tür oyunlardan ise en fazla Wii-Fit ve Wii-Sport gibi oyun modülleri bulunan Nintendo Firmasının üretmiş olduğu Wii platformunun çalışma konusu olduğu görülmektedir.

Yapılan çalışmalarda Serebral palsi, Koah, ihmal sendromu ve parkinson tedavisi için Wii platformu; hemodinamik bozukluk, ihmal sendromu, Otizm, Koah için Kinect; el bileğinde kırık, Diyabet, çoklu skleroz, Kanser tedavisi, Perioperatif Ağrı ve Anksiyete için PC ve dış donanımları; Koah ve parkinson tedavileri için ise tablet (mobil) platform ve akrofobi tedavisi için sanal gerçeklik platformları kullanılmıştır.

Genellikle Nintendo Wii ve Kinect gibi aktif video oyunların daha çok tercih edilmesinin, tamamen fizyolojik etkileşime dayalı oyun platformları olduğundan kaynaklandığı düşünülmektedir.

\section{3. Örneklem Gruplarına Dair Bulgular:}

İncelenen araştırmalara dahil edilen örneklemler, yaş durumuna göre üç kategoriye ayrılmıştır: Çocuk (0-18 Yaş), yetişkin (19-60 Yaş) ve yaşlı (61+ yaş). Araştırmalardaki örneklemlerin dağılımı Tablo 3'te yer almaktadır.

Tablo 3. Örneklem yaş gruplarının dağılımı

\begin{tabular}{lcc}
\hline Yaş Grubu & Frekans & Etkili Olan Çalışma Sayısı: \\
\hline Çocuk (0-18 Yaş) & 9 & 7 \\
Yetişkin (19-60 Yaş) & 6 & 4 \\
Yaşlı (61+ yaş) & 6 & 4 \\
Toplam & $\mathbf{2 1}$ & $\mathbf{1 5}$ \\
\hline
\end{tabular}

Tablo 3' te görüldüğgü üzere tedavi ve rehabilitasyon amaçlı oyunların kullanımı en fazla 0-18 yaş aralığında görülmektedir ve bunu sirasıyla 61+ ve 19-60 takip etmektedir.

İncelenen çalışmalarda çocuk(0-18) grubunun Serebral palsi, Kol ve el fiziksel rehabilitasyonu, Diyabet, Kanser tedavisi, Otizm, Perioperatif ağrı ve anksiyetenin oyunla tedavi ve rehabilite edilmesi amaçlanırken, yetişkin(19-60) grubunun hemodinamik bozukluk, KOAH, El bileğinde kırık, çoklu skleroz, ihmal sendromu ve Akrofobinin oyunla tedavi ve rehabilitasyon 
edilmesi ve Yaşlı (61+) grubunun denge kaybı, Parkinson, KOAH ve Alzheimer'ın oyunla tedavi ve rehabilitasyon edilmesi amaçlanmıştır.

\section{4. Çalışmaların Etkililiğine İlişkin Bulgular:}

Oyunların tedavi edici etkilerini araştıran bu çalışmaya dahil edilmiş 21 deneysel çalışma, oyunun istatistiksel anlamda etkisinin olup olmaması sonucuna göre Tablo-4'te gösterilmiştir.

Tablo 4. Çalışmaların etkililiğinin frekans dağılımı

\begin{tabular}{ll}
\hline Sonuç: & Frekans: \\
\hline Tedavide Etkisi Olmuştur & 15 \\
Anlamlı Bir Etkisi Yoktur & 6 \\
Toplam & $\mathbf{2 1}$ \\
\hline
\end{tabular}

Tablo 4'te görüldüğü üzere oyun ile tedavi ve rehabilitasyon amaçlı 21 çalışmanın 15'inde oyunların tedavide etkili olduğu görülürken, 6 çalışmada oyunların tedavide anlamlı bir etkisinin olmadığı görülmektedir.

Yapılan çalışmalarda oyunların Serebral palsi, el bileğinde kırık, kol ve el fiziksel rehabilitasyonu, çoklu skleroz, ihmal sendromu, Kanser tedavisi, Akrofobi, Otizm, Parkinson, Perioperatif ağrı ve anksiyete, $\mathrm{KOAH}$, diyabet ve Alzheimer için tedavi edici etkisinin olduğu bulgusuna ulaşlırken, hemodinamik bozukluk ve yaşlılarda denge kaybı hastalıkları için anlamlı bir etkisinin olmadığı gözlemlenmiştir. Koah, Parkinson ve Serebral Palsi ile ilgili farklı sonuçlar içeren çalışmalar mevcuttur.

\section{SONUÇ VE TARTIŞMA:}

Bulgular göstermektedir ki; dijital oyunların sağlık alanında bilişsel ve fizyolojik destek amacıyla kullanımı son dönemde oldukça umut vericidir. Yapılan deneysel çalışmaların etkililiği göz önünde bulundurulduğunda, sonuçlar oyunların birçok farklı hastalıkta olumlu olduğunu göstermektedir. İncelenen çalışmalarda kullanılan deneklerin yaş grubu açısından farklılık göstermesi, dijital oyunların çocuk, genç, yaşlı fark etmeksizin tüm yaş gruplarında kullanılabileceği sonucunu göstermektedir.

Dijital oyun kullanımının anlamlı düzeyde etkisinin olmadığı bulgusuna ulaşan araştırmacıların bile oyunlar konusunda hemfikir olduğu bazı noktalar mevcuttur. Bunlardan en önemlisi de motivasyon unsurudur (Allen vd., 2017; Brito-Gomes vd., 2018; Jonsdottir vd., 2019). Tedavilerin genellikle acı veren süreçler olduğu düşünüldüğünde, oyun oynamanın 
tedavi sürecini anlamlı olarak bir etkisi olmasa bile oyunların zevk ve motivasyon unsurları ile bireyleri tedavi sürecinde daha katılımcı hale getirdikleri görülmüştür (Matthyssens vd., 2019). Kaldı ki; oyunların etkili olmadığı sonucuna ulaşan araştırmalarda; örneklem grubunun sosyo-ekonomik düzeyi, psikolojik altyapıları, oyun tecrübeleri, doğru oyun seçimi gibi birçok değişkenin analiz edilmesi ve tedavi süreçlerinin bunlara uygun hale getirilmesi ile bu sonuçların değişmesi mümkündür. Ayrıca çalışmaların kısa süreli olarak yürütülmesinin bu tür sonuçların çıkmasında etkili olduğu tahmin edilmektedir.

İncelenen çalışmalarda dikkat çeken noktalardan biri de platform ve oyun seçimleridir. Bilgisayar ve sanal gerçeklik ortamlarında hastalık üzerindeki etkisi gözlenen oyunlardan bazıları yapılan akademik çalışma için özel geliştirilmiştir (Fuchslocher vd., 2011; Manera vd., 2015; Zago vd., 2019). Var olan hazır bir oyun kullanmak yerine, özel olarak hastalığa yönelik oyun geliştirme ve bunun etkileri farklı bir araştırma konusu olmakla beraber bu konu oldukça geniş bir çalışma ekibi (Sağlık Uzmanları, Bilişimciler, Oyun Tasarımcıları, Mühendisler vs.) ve kompleks bir çalışma gerektirir. Ayrıca bu tür çalışmalar oldukça maliyetli olacaktır ki; oyunların etkili olduğu tespit edilen çalışmalarda bile araştırmacılar çalışmaların maliyetleri konusunda şerh düşmüşlerdir (Emmelkamp vd., 2001).

Sanal gerçeklik, kurgu ve teknoloji kullanılarak gerçek ve hayalin birleştirilmesiyle, sanal çevrede kişiye herhangi bir durumun içinde onu yaşıyormuş hissi vererek ekstra bir boyut sunan ortamlar olarak tanımlanırken (Fuchs, Moreau \& Guitton, 2011), artırılmış gerçeklik ise cihazların cisim tanıma özelliği kullanılarak, sanal nesnelerin gerçek görüntülerin üzerine bindirildiği ortamlardır. Tıp dünyasında sanal gerçeklik uygulamalarının ilk kullanımı, ruhsal hastalıkların (Yükseklik korkusu vb.) tedavisi ile birlikte 1993'te olmuştur (Wiederhold, 2006). Her ne kadar bu çalışmada odak olarak aktif video oyunları (Kinect-wii vb.) yer alsa da son dönemde sağlık alanında kullanımı ve önemi artan dijital uygulamalar arasında sanal gerçeklik (VR) ve artırılmış gerçeklik (AR) de göze çarpmaktadır (Huang, Yang, Hsieh, Wang\& Hung, 2018). Bu uygulamalar hem eğitim hem de cerrahi / tedavi / rehabilitasyon amaciyla yapılabilmektedir (David, Arman, Chandra\& Nadia, 2019; Tu, Hao, Bi\& Xing, 2019) Psikolojik bozuklukların tedavisinde işlevsel olmaları ve riskli cerrahi operasyonlarda simülasyon olanağı tanıyarak hasta güvenliğine katkı sağlamaları gibi avantajlar, VR ve AR uygulamalarının sağlık alanında giderek daha fazla öne çıkmasına yol açmaktadır (Cieślik, Mazurek, Rutkowski, Kiper, Turolla\& Szczepańska-Gieracha, 2020; Gaba, 2004). Tüm bu katkılarıyla beraber VR ve AR uygulamalarının sağlık alanında kullanımı Türkiye' de oldukça yeni ve gelişime açık bir durumdadır. Türkiye için de sağlık çalışanlarına eğitim veren kurumlarda, gerek verilen eğitimin niteliğini arttırmak, gerekse çağın teknolojik gelişmelerine de uyum sağlamak adına, eğitim müfredatlarına VR ve AR uygulamalarının dahil edilmesi ve kullanımının yaygınlaştırılması önerilmektedir (Sarıkoç, 2016).

Dijital sağlık alanında, dijital oyunların daha fazla kullanımı için sağlık çalışanları ve politikacılar tarafından sağlanan diğer girişimlerin yanı sıra bu opsiyon da önemsenerek göz 
önüne alınmalıdır. Diğer teknolojilerde olduğu gibi, dijital sağlık oyunlarının da geleceğini tahmin etmek zor olsa bile, gelecekte sağlık oyunları tablet ve mobil cihazlarla uyumlu hale gelecektir. Kullanılan donanımlar (Sensörler, aparatlar, vs.) ve mobil uygulamalar arttıkça, dijital oyunların sağlık amaçlı olarak günlük hayatta kullanımı artacak ve dünya pazarında bu tür oyunlar daha fazla paya sahip olacaktır.

\section{Kaynakça:}

Akbulut, A., (2015). Bilgisayar Destekli Otizm Terapi Sistemi Tasarımı. Tip Teknolojileri Ulusal Kongresi, TIPTEKNO'15, At Mugla, Turkey, 15-18 October 2015.

Allen, N. E., Song, J., Paul, S. S., Smith, S., O'Duffy, J., Schmidt, M., ... \& Canning, C. G. (2017). An interactive videogame for arm and hand exercise in people with Parkinson's disease: A randomized controlled trial. Parkinsonism \& related disorders, 41, 66-72.

Avşar, Z., \& Kadriye, A. V. C. I. Dijital Sağlık Oyunları. TRT Akademi, 1(2), 472-486.

Bateni, H. (2012). Changes in balance in older adults based on use of physical therapy vs the Wii Fit gaming system: a preliminary study. Physiotherapy, 98(3), 211-216.

Bayırtepe, E., \& Tüzün, H. (2007). Oyun-tabanlı öğrenme ortamlarının öğrencilerin bilgisayar dersindeki başarıları ve öz-yeterlik algıları üzerine etkileri. Hacettepe Üniversitesi Ĕ̆itim Fakültesi Dergisi, 33(33), 41-54.

Betker, A. L., Szturm, T., Moussavi, Z. K., \& Nett, C. (2006). Video game-based exercises for balance rehabilitation: a single-subject design. Archives of physical medicine and rehabilitation, 87(8), 1141-1149.

Birn, T., Holzmann, C., \& Stech, W. (2014, June). MobileQuiz: A serious game for enhancing the physical and cognitive abilities of older adults. In International Conference on Universal Access in HumanComputer Interaction (pp. 3-14). Springer, Cham.

Brito-Gomes, J. L. D., Perrier-Melo, R. J., Brito, A. D. F., \& Costa, M. D. C. (2018). Active videogames promotes cardiovascular benefits in young adults? Randomized controlled trial. Revista Brasileira de Ciências do Esporte, 40(1), 62-69.

Cannon-Bowers, J. A., Bowers, C., \& Procci, K. (2011). Using video games as educational tools in healthcare.

Ciddi, P. (2018). Serebral Palsili Çocuklarda Video Temelli Oyun Tedavisinin Tedavi Yoğunluğuna Etkisi.

Cieślik, B., Mazurek, J., Rutkowski, S., Kiper, P., Turolla, A., \& Szczepańska-Gieracha, J. (2020). Virtual reality in psychiatric disorders: A systematic review of reviews. Complementary Therapies in Medicine, 102480.

David, D., Arman, E., Chandra, N., \& Nadia, N. (2019). Development of Escape Room Game using VR Technology. Procedia Computer Science, 157, 646-652.

Emmelkamp, P. M., Bruynzeel, M., Drost, L., \& van der Mast, C. A. G. (2001). Virtual reality treatment in acrophobia: a comparison with exposure in vivo. CyberPsychology \& Behavior, 4(3), 335-339.

Fuchs, P., Moreau, G., \& Guitton, P. (Eds.). (2011). Virtual reality: concepts and technologies. CRC Press. 
Fuchslocher, A., Niesenhaus, J., \& Krämer, N. (2011). Serious games for health: An empirical study of the game "Balance" for teenagers with diabetes mellitus. Entertainment Computing, 2(2), 97-101.

Gaba, D. M. (2004). The future vision of simulation in health care. BMJ Quality \& Safety, 13(suppl 1), i2i10.

Gordon, C., Roopchand-Martin, S., \& Gregg, A. (2012). Potential of the Nintendo Wii ${ }^{\mathrm{TM}}$ as a rehabilitation tool for children with cerebral palsy in a developing country: a pilot study. Physiotherapy, 98(3), 238-242.

Grossard, C., Grynspan, O., Serret, S., Jouen, A. L., Bailly, K., \& Cohen, D. (2017). Serious games to teach social interactions and emotions to individuals with autism spectrum disorders (ASD). Computers \& Education, 113, 195-211.

Güvenli İnternet Merkezi (2019). “2019 Yılı Dijital Oyunlar Raporu” Erişim Tarihi: 20 Mart 2020, https://www.guvenlioyna.org.tr/galeri-detay/dijital-oyunlar-raporu-2019

Hall, A. K., Chavarria, E., Maneeratana, V., Chaney, B. H., \& Bernhardt, J. M. (2012). Health benefits of digital videogames for older adults: a systematic review of the literature. Games for Health: Research, Development, and Clinical Applications, 1(6), 402-410.

Herz, N. B., Mehta, S. H., Sethi, K. D., Jackson, P., Hall, P., \& Morgan, J. C. (2013). Nintendo Wii rehabilitation ("Wii-hab") provides benefits in Parkinson's disease. Parkinsonism \& related disorders, 19(11), 1039-1042.

Hansen, L., Sanders, S. (2008). Interactive gaming: Changing the face of fitness. Florida Alliance for Health, Physical Education, Recreation, Dance \& Sport Journal, 46(1), 38-41.

Huang, T. K., Yang, C. H., Hsieh, Y. H., Wang, J. C., \& Hung, C. C. (2018). Augmented reality (AR) and virtual reality (VR) applied in dentistry. The Kaohsiung journal of medical sciences, 34(4), 243248.

Huizinga, J. (1938). Homo ludens. Vom ursprung der kultur im spiel, 19.

Jonsdottir, J., Perini, G., Ascolese, A., Bowman, T., Montesano, A., Lawo, M., \& Bertoni, R. (2019). Unilateral arm rehabilitation for persons with multiple sclerosis using serious games in a virtual reality approach: Bilateral treatment effect?. Multiple sclerosis and related disorders, 35, 76-82.

Kaya, P., \& Yılmaz, Ö. T. Serebral Palsi'de İnteraktif Video Oyunlarının Denge ve Performans Üzerine Akut Etkisi. Ergoterapi ve Rehabilitasyon Dergisi, 6(2), 95-104.

Krefting, L. (1991). Rigor in qualitative research: the assessment of trustworthiness. The American Journal of Occupational Therapy, 45(3), 214-222.

Kurt, A. S., \& Savaşer, S. (2013). Kanserli adölesanların yaşam kalitesi düzeyine Re-Mission video oyununun etkisi. Turkish Journal of Oncology/Türk Onkoloji Dergisi, 28(2).

Manera, V., Petit, P. D., Derreumaux, A., Orvieto, I., Romagnoli, M., Lyttle, G., ... \& Robert, P. H. (2015). 'Kitchen and cooking,'a serious game for mild cognitive impairment and Alzheimer's disease: a pilot study. Frontiers in aging neuroscience, 7, 24.

Matthyssens, L. E., Vanhulle, A., Seldenslach, L., Vander Stichele, G., Coppens, M., \& Van Hoecke, E. (2019). A pilot study of the effectiveness of a serious game CliniPup ${ }^{\circledR}$ on perioperative anxiety and pain in children. Journal of pediatric surgery. 
Marks, D. W., Rispen, L., \& Calara, G. (2015). Greater physiological responses while playing XBox Kinect compared to Nintendo Wii. International Journal of Exercise Science, 8(2), 7.

McCallum, S., \& Boletsis, C. (2013, September). Dementia Games: a literature review of dementia-related Serious Games. In International Conference on Serious Games Development and Applications (pp. 1527). Springer, Berlin, Heidelberg.

Pompeu, J. E., dos Santos Mendes, F. A., da Silva, K. G., Lobo, A. M., de Paula Oliveira, T., Zomignani, A. P., \& Piemonte, M. E. P. (2012). Effect of Nintendo Wii ${ }^{\mathrm{TM}}$-based motor and cognitive training on activities of daily living in patients with Parkinson's disease: A randomised clinical trial. Physiotherapy, 98(3), 196-204.

Rutkowski, S., Rutkowska, A., Jastrzębski, D., Racheniuk, H., Pawełczyk, W., \& Szczegielniak, J. (2019). Effect of Virtual Reality-Based Rehabilitation on Physical Fitness in Patients with Chronic Obstructive Pulmonary Disease. Journal of human kinetics, 69, 149.

Sarıkoç, G. (2016). Sağlık Çalışanlarının Eğitiminde Sanal Gerçekliğin Kullanımı. Koç Üniversitesi Hemşirelikte Eğitim ve Araştırma Dergisi (HEAD), 13(1), 11-15.

Sevimli-Celik, S., Kirazci, S., \& Ince, M. L. (2011). Preschool movement education in Turkey: Perceptions of preschool administrators and parents. Early Childhood Education Journal, 39(5), 323.

Sezer, L. (2009). Development of a virtual reality based physically interactive game system for virtual rehabilitation with a case study (Doctoral dissertation, M. Sc Thesis, Atılım University Computer Engineering, Ankara).

Surer, E., Pirovano, M., Mainetti, R., Tatti, F., Baud-Bovy, G., \& Borghese, A. (2014, April). Video-games based Neglect rehabilitation using haptics. In 2014 22nd Signal Processing and Communications Applications Conference (SIU) (pp. 1726-1729). IEEE.

Sutanto, Y. S., Makhabah, D. N., Aphridasari, J., Doewes, M., \& Ambrosino, N. (2019). Videogame assisted exercise training in patients with chronic obstructive pulmonary disease: A preliminary study. Pulmonology.

Thompson, D., Baranowski, T., Buday, R., Baranowski, J., Thompson, V., Jago, R., \& Griffith, M. J. (2010). Serious video games for health: How behavioral science guided the development of a serious video game. Simulation \& gaming, 41(4), 587-606.

Tu, L., Hao, T., Bi, C., \& Xing, G. (2019). BreathCoach: A smart in-home breathing training system with bio-feedback via VR game. Smart Health, 100090.

Valladares-Rodriguez, S., Fernández-Iglesias, M. J., Anido-Rifón, L., Facal, D., Rivas-Costa, C., \& PérezRodríguez, R. (2019). Touchscreen games to detect cognitive impairment in senior adults. A user-interaction pilot study. International journal of medical informatics, 127, 52-62.

Vernadakis, N., Gioftsidou, A., Antoniou, P., Ioannidis, D., \& Giannousi, M. (2012). The impact of Nintendo Wii to physical education students' balance compared to the traditional approaches. Computers \& Education, 59(2), 196-205.

Webster, D., \& Celik, O. (2014). Systematic review of Kinect applications in elderly care and stroke rehabilitation. Journal of neuroengineering and rehabilitation, 11(1), 108.

Wiederhold, B. K. (2006). The potential for virtual reality to improve health care. The Virtual Reality Medical Center.

Xbox-Microsoft (2019). "Genel Bilgiler Kinect" Erişim Tarihi: 20 Mart 2020, https://support.xbox.com/tr-TR/browse/xbox-360/getting-started/Kinect 
Yen, C. Y., Lin, K. H., Hu, M. H., Wu, R. M., Lu, T. W., \& Lin, C. H. (2011). Effects of virtual realityaugmented balance training on sensory organization and attentional demand for postural control in people with parkinson disease: a randomized controlled trial. Physical therapy, 91(6), 862-874.

Yıldırım, A. \& Şimşek, H. (2005). Sosyal bilimlerde nitel araştırma yöntemleri. Ankara: Seçkin.

Zago, N. N., de Souza, L. A. P. S., Kimura, B. G., Bertoncello, D., Grecco, M. A. S., \& Fernandes, L. F. R. M. (2019). Serious games therapy associated with conventional physical therapy intervention accelerated hand muscles strengthening and hand functioning after complex fracture of the wrist: A case report. Journal of Hand Therapy. 